\title{
Doing Justice to Human Security: A Textbook in Tune with its Time
}

Published: 4 September 2013

Keywords: an appropriate human security textbook; learning outcomes and big ideas

\author{
Human Security in World Affairs: Problems \\ and Opportunities \\ Alexander K. Lautensach, Sabina W. Lautensach \\ (eds.) \\ Caesarpress: 2013 \\ 504 pp.; ISBN: 978-3-902890-00-9
}

I begin this brief review of this important volume with the confession that I have not personally pursued a teaching style that has employed a self-acclaimed textbook for many, many years, preferring to construct courses around monographs, articles and other visual materials. However, were I provided the opportunity to teach a course at the upper division undergraduate level or early gradate level in the subject of human security, this would certainly be the book I would choose (with the caveat introduced below). Alex and Sabina Lautensach have given careful and thoughtful consideration to every aspect of the text: the preface and introduction, written by the editors, lay out both the logic of the text and frame the subject matter that will locate the reader firmly in the midst of the vast challenges that constitute the issue of human security. They do so by emphasizing both the multiple dimensions along which the issue of human security can be located and the inseparable nature of these as they interact with each other in complex ways. In many respects this strikes me as one of the most important contributions to the text-its steady insistence that human security as a construct is in a discursive state of constant emer- gence, such that in some important ways all its varied dimensions insistently co-vary. To make such a claim is in itself daunting - to demonstrate its validity and mutual engagements through the complex subject matters of its 20 chapters, is a tour de force. Their conclusion is sufficiently rich to stand alone as an illustrative text in other course materials.

As a text the book is thoughtfully constructed. As indicated, the subject matter chapters are preceded by a preface and introduction that are written in a style that is welcoming to the reader and leave one with a sense of confidence that the overall work promises both purpose and content that will be rewarding. For the student this promise is realized in the structure of the 19 content chapters. Each consists of a summary that appears at the beginning of the chapter followed by a statement of "Learning Outcomes and Big Ideas". This framing device gives on to the overall subject matter of the chapter, conveniently identified by specific enumerated sections. Each chapter concludes with four teaching-oriented subsets: summary points that ably delineate the major issues touched on within the chapter; a listing of extension activities and further research ideas that stimulate the reader/ learner to additional activities; a list of terms and definitions that cumulatively build the conceptual vocabulary that is a major "take away" of the volume; and a section on further reading which often contains useful URLs to direct the reader to sites that in their nature will continuously update concepts and materials found within the chapter.

One can only be impressed by the reach of this volume and the impressive credentials of its many 
authors. The conventional listing of contributors at the volume's end provides an additional incentive for readers to extend their investigation beyond the volume in hand by putting these authors high on their list of future reading. They include an impressive mix of academic credentials as well as ample "real world" postings in both governmental and NGO sites throughout the world. Perusing this listing one can not help but carry away from it not only the sense of wellearned credentialization of the contributors, but also their commitments to the numerous and varied issues and causes that necessarily make up the "culture" of human security endeavors throughout the world.

Given the inevitable "reality" that to address human security is to "take on" virtually every aspect of human activity on the globe in all time periods, the volume does a remarkable job of selecting areas of concentration that will provide a rapid learning experience for the novice reader (let alone the additional benefits of reach and edification that come to the more experienced reader). This benefit is, I think, best exemplified by the constant iteration of the interactions that exist between human and nonhuman environmental factors. The direct and indirect interfaces between human settlement activity of all sorts-but especially those of human societies over the past two hundred years-and the natural environment are touched on in nearly every chapter with the result that the reader's previous understanding of key concepts is simultaneously reinforced and expended upon. Phrased another way, the framing with which the volume leads-namely, providing effective understanding of both the reach and limitations of various environments and ecologies throughout the globe-is constantly overlain with rich and complex descriptions and analyses of complex human structures that have grown out of such engagements both as efforts to organize and regulate them, e.g. state structures, extra-state structures, laws, conventions, regulatory processes, as well as those that exist outside the reach of effective human regulation and continue as the sources of human misery and constant threats to human security, e.g. human trafficking, arms dealing, global crime, refugee displacement, health threats, etc. Overall, as a reader I was impressed by the extraordinary range of the conceptual structures provided by the volume as well as the wealth of information provided.

As a university classroom teacher of many decades, I was constantly challenged in reading this volume to think of how it could be effectively used by my students. I am struck by three accommodations one must make to it. First, despite the very original and diligent structural considerations built into each chapter intended to assist the student in grasping the extraordinary range of materials included in the volume, I find the task viewed from the student's perspective daunting. This flows both from the range of the subject matter and the extraordinary detail that is provided differentially in virtually every chapter. In many respects I would conceive of the book more as a resource volume than a text, certainly at the undergraduate level. Second, I write from a distinctly American university perspective wherein most university undergraduate curricula would not have provided a ready administrative space for a multidisciplinary subject such as human security: it would most likely be taught either from a social science, biological science or health science perspective. As such the teaching task is considerable to assure that students have the grasp of the theoretical and conceptual materials necessary to ensure full use of the book. To which one needs to add that both the semester and quarter structure of many (most?) courses make this a heavy burden for most undergraduate classes. I hasten to admit that this reflects more negatively on the nature of US undergraduate educational structures than on the inherent value of the book, but as I indicate, it is a significant accommodation one must make were this the context of its use. Thirdly, and following directly from my previous point, in my own teaching this would be an invaluable book at the graduate level, in any number of courses. Within my own frame of reference its use in courses in policy, conflict, globalization, planning and health would be more than welcome.

Given my obvious appreciation of the book and its many virtues, it seems almost gratuitous to focus on what I find as shortcomings. But for my purposes both as a university teacher and researcher, I find several areas in which I would have appreciated either inclusion of an added dimension or greater attention within chapters that occupy these subject frames. One is with the issue of population. Whereas the extraordinary challenges presented by our current population trajectory are touched on in various places (most particularly chapter two), as an overall driver of the human security complex of causes and effects, it seems to be under-emphasized and valued. This is especially true given the precise point we occupy on the population explosion curve. Our students in particular are facing a world of potential transition that is almost without recent precedent. Combining this awareness with a more extended consideration of the dynamics of the global economy into which our students will be entering seems especially relevant. This leads to a second and related concern, which again is touched on in various places, especially those that deal with issues of the state and extra-state status, namely the explosive growth throughout the world of conurbations, sometimes viewed as mega cities. A growing amount of recent scholarship, especially from urbanists and students of globalization suggests that the structural nature of such human aggregations poses new issues and dilemmas for governance and survival. My suggestion is that they need to be included within this admirable catalogue of human security concerns in and of themselves. A third 
issue concerns the ubiquitous nature of technological change and its transformations throughout the complete range of knowledge environments. The dominant view of technology throughout the volume tends to be its threats to issues of sustainability between human and non-human ecologies. My view is that the world as we know it is poised at a particular conjuncture between population, human settlement patterns, governance and belief and the ever more rapidly changing knowledge environment-all part of the collective phenomenon we choose to label globalization despite our ready admission that by this term we mean many, many different things.
But in the overall context of this admirable volume, these can be viewed as perhaps desirable additions to a second edition, rather than as shortcomings that detract from its value. Overall, the volume is an extraordinary achievement and I applaud its publication.

Deane E. Neubauer

Department of Political Science, University of Hawaii, Manoa, HI, USA; E-Mail: deanen@hawaii.edu 